\title{
Quasi-static and cyclic compressive loading studies of the intervertebral disc with combined flexion and torsion
}

\author{
Helio Schechtman*, Peter Alexander Robertson, Neil David Broom
}

\begin{abstract}
Bovine caudal motion segments were used to investigate the loss of load-bearing ability of the intervertebral disc (IVD) under both quasi-static and cyclic compressive loading combined with torsion and flexion. While the response of the disc to both compressive hyper-flexion and hyper-torsion has been previously investigated much less is known about their individual and combined influence on compressive failure. Eighty motion segments dissected from 41 bovine tails were subjected to quasi-static and cyclic compression with added components of flexion and torsion. The four different combinations of flexion and torsion were $0^{\circ}$ torsion $/ 0^{\circ}$ flexion, $10^{\circ}$ torsion $/ 15^{\circ}$ flexion, $10^{\circ}$ torsion $/ 0^{\circ}$ flexion and $0^{\circ}$ torsion $/ 15^{\circ}$ flexion. Quasi-static compression failed to show any significant difference among the different combinations of torsion and flexion for failure stress, failure strain and compressive tangent modulus. Cyclic compression indicated a significant influence of torsion in reducing the disc's load-bearing ability. Cyclic loading provides a more sensitive tool for the assessment of potentially damaging mechanical parameters for the IVD.
\end{abstract}

Keywords Intervertebral disc, Quasi-static compression, Cyclic compression, Torsion, Flexion.

\section{Estudo da compressã̃o monotônica e cíclica associada à flexão e torção do disco intervertebral}

Resumo Segmentos de cauda bovina foram utilizados para investigar a perda de capacidade de suporte de carga do disco intervertebral (IVD) sob compressão monotônica e cíclica combinada com torção e flexão. Embora a resposta do disco a hiper-flexão e hiper-torção compressiva já fora previamente investigada, pouco se conhece sobre suas influências individuais e combinada para a falha compressiva. Oitenta segmentos dissecados a partir de 41 caudas bovina foram submetidos a compressão monotônica e cíclica com componentes adicionais de flexão e de torção. As quatro combinações diferentes de flexão e torção foram $0^{\circ}$ torção $/ 0^{\circ}$ flexão, $10^{\circ}$ torção $/ 15^{\circ}$ flexão, $10^{\circ}$ torção $/ 0^{\circ}$ flexão e $0^{\circ}$ torção $/ 15^{\circ}$ flexão. A compressão monotônica não evidenciou qualquer diferença significativa entre as diferentes combinações de torção e flexão para tensão de ruptura, deformação em ruptura e módulo tangente. A compressão cíclica indicou influência significativa da torção na redução da capacidade de carga do disco intervertebral. A carga cíclica proporciona uma ferramenta sensivel para a avaliação de parâmetros mecânicos potencialmente deletérios ao IVD.

Palavras-chave Disco intervertebral, Compressão monotônica, Compressão cíclica, Flexão, Torção. 


\section{Introduction}

The intervertebral disc (IVD) is a complex structure that allows load bearing, limits intervertebral motion, and maintains anatomic relationships of surrounding bony vertebral bodies and ligamentous structure (Skaggs et al., 1994). Mechanical failure of the disc might be the result of traumatic overloading. Alternatively, it could be the result of a slow degenerative process that alters the mechanical properties of the disc, increasing its vulnerability to disruption when subjected to loads substantially lower than that required to induce a traumatic injury.

Adams and Hutton (1982) have shown that hyper-flexion combined with axial compressive loads could produce prolapse of the disc in vitro. Farfan et al. (1970) damaged the disc annulus by applying axial hyper-rotation. Gordon et al. (1991) investigated cyclic loading and rotation of fully flexed lumbar motion segments. These investigators were able to induce annular protusions and nuclear extrusion through annular tears.

Failure of motion segments in cyclic loading has been achieved by a combination of cyclic loading and flexion (Adams and Hutton, 1983, 1985; Callaghan and McGill, 2001; Hansson et al., 1987). Others have investigated the influence of torsion (Gordon et al., 1991; Liu et al., 1985).

However, the individual influence of hyper-flexion, i.e. flexion beyond the physiological range (Gordon et al., 1991) of $9^{\circ}$, or hyper-rotation, i.e. rotation beyond $3^{\circ}$, either in single or cyclic compressive loads, was not properly assessed in any of the above mentioned studies.

Loss of a disc's load-bearing ability can be assessed in a variety of ways. Complete closure of the endplate separation could be used for such a purpose under quasi-static compression. Under cyclic loading involving displacements less than the endplate separation an appropriate failure parameter is considerably more difficult to define.

One possible approach is to use the internal pressure generated in the disc by the subject as a fundamental reference value against which cyclically generated stresses can be compared. In the human lumbar disc $2 \mathrm{MPa}$ is an average value of the internal pressure generated by the subject's normal in vivo activities (Nachemson and Elfström, 1970). Under displacement-controlled cyclic loading, if the externally imposed stress drops below this $2 \mathrm{MPa}$ value, then endplate closure in vivo would be deemed to occur as a result of this physiological loading. Under displacement-controlled loading the number of cycles required to reduce the initial level of externally induced stress to this $2 \mathrm{MPa}$ value can be conveniently defined as the threshold value for the loss of load-bearing ability of the IVD.

The present paper reports on an investigation into the effects of hyper-flexion and hyper-rotation on the load-bearing ability of the IVD when it is subjected to single or cyclic axial compressive loading. We have used the endplate closure criterion as a means of defining the point of ultimate compressive stress above which quasi-static failure would have occurred. Secondly, we have employed the criterion of stress decay to the value of $2 \mathrm{MPa}$ to define the threshold life (in number of cycles) of the disc under displacement controlled cyclic loading.

\section{Materials and Methods}

Prime ox tails were obtained at the local abattoir. The tails were immediately wrapped in plastic film and kept at $-20{ }^{\circ} \mathrm{C}$ until the day prior to mechanical testing. The tail was then removed from the freezer into a refrigerator and stored overnight at a temperature of $+4{ }^{\circ} \mathrm{C}$ for slow thawing. Motion segments comprising an intervertebral disc and its adjoining two vertebrae were obtained from the tails and cleaned of all subjacent tissue. The bone processes of both vertebrae were then trimmed off. Each vertebral body was set in cylindrical stainless steel pots $(\varnothing 50 \times 50 \mathrm{~mm})$ using dental plaster, with the disc and pot axes coaxial. Prior to any mechanical testing the potted motion segment was hydrated in physiological saline for 12 hours at $+4{ }^{\circ} \mathrm{C}$. The endplate gap separation was measured radiographically. The external diameter of the IVD was measured with a vernier caliper and its value employed in the calculation of its cross-sectional area.

A specially designed adjustable rig was employed to mount the potted motion segment onto a dynamic testing machine (model 810-50 kN, MTS Systems, USA). This rig enabled fixed degrees of flexion and torsion to be applied to the IVD. Figure 1 depicts the rig with a specimen mounted in a state of flexion and torsion. The maximum range of motion allowed for both in flexion and torsion was $20^{\circ}$. In order to ensure that the applied compressive load did not generate any additional bending moment other than that applied formally by any given amount of flexion, the rig allowed free lateral sliding in the plane of flexion of the upper potted end. All flexion was applied anteriorly in the sagittal plane. The lower potted end could be rotated axially to provide varying degrees of torsion along the longitudinal axis of the IVD. The rig clamps were then able to be locked to provide a defined amount of flexion and torsion. 
Quasi-static tests: The testing machine was operated in displacement control with the actuator moving at a rate of $0.5 \mathrm{~mm} / \mathrm{s}$. The specimens were mounted in the rig and compressed well beyond the point of endplate gap closure to ensure complete failure of the motion segment. It was assumed that all the compressive strain up to endplate gap closure occurred only in the IVD. Beyond endplate gap closure the compressive strain was assumed to be derived from the bony structures of the vertebrae.

These quasi-static compressive tests were conducted in combination with each of the following loading regimes: $0^{\circ}$ flexion, $0^{\circ}$ torsion (F0T0); $15^{\circ}$ flexion, $0^{\circ}$ torsion (F15T0); $0^{\circ}$ flexion, $10^{\circ}$ torsion (F0T10); and $15^{\circ}$ flexion, $10^{\circ}$ torsion (F15T10). Test specimens were randomly allocated into each one of these four loading regimes.

Load and displacement were continuously recorded. The maximum compressive stress was calculated as the load at failure divided by the cross-sectional area of the IVD. Strain at failure was based on the initial endplate gap distance. The compressive modulus was calculated as the tangent to the linear portion of the stress-strain curve relating to the displacement achieved prior to end-plate closure. A total of 40 motion segments obtained from 21 tails were employed in these quasi-static compressive tests.

Cyclic loading: For these tests the specimens were kept moist throughout the experiment by wrapping them in paper towel soaked with $0.15 \mathrm{M}$ saline solution. The testing machine imposed a compression-compression displacement sinus at $2 \mathrm{~Hz}$. The minimum displacement was $0.5 \mathrm{~mm}$ and the maximum value was set at $2 / 3$ of the endplate gap separation. The cyclic tests were carried out using each one of the four loading regimes as described above for the quasi-static tests. Specimens were randomly allocated to each one of the four loading regimes.

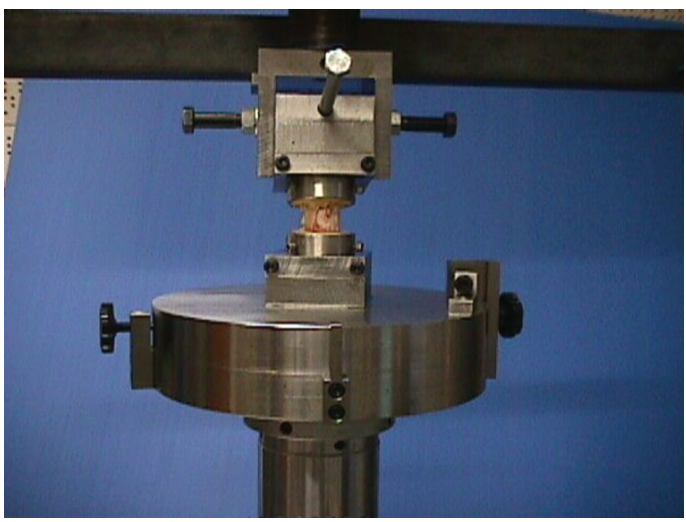

Figure 1. Detail of the compression loading rig designed to incorporate added components of flexion and/or torsion, with motion segment in place.
However, in order to allow a paired t-test statistical analysis, each one of the two specimens from a given tail was allocated to one of the loading regimes of the pair F0T0/F15T10 or F15T0/F0T10. The cyclic load was recorded continuously. The test was terminated when the recorded maximum load imposed on the specimen decayed to a value equivalent to a stress of $2 \mathrm{MPa}$ based on the measured external diameter of the disc. A total of 40 motion segments from 20 tails were tested cyclically.

\section{Results}

Quasi-static tests: Figure 2 shows a typical stress versus strain response for quasi-static compression of a motion segment. The curve has an initial non-linear region of low modulus leading into a relatively linear, stiffer region. The inflexion point following this linear region corresponds with the closure of the endplate gap. These first three regions therefore define the compressive response of the IVD itself. Further compressive displacement beyond endplate closure, i.e. beyond the inflexion point, would require compression of the vertebrae. The relatively flat region beyond the inflexion point would represent compaction through crushing of the trabecular architecture, and the steep region following would correspond to the increased stiffness arising from this increasingly compacted bone structure. Table 1 shows for each disc the diameter, endplate gap, ultimate compressive stress, strain at failure and compressive modulus for the four different loading regimes employed.

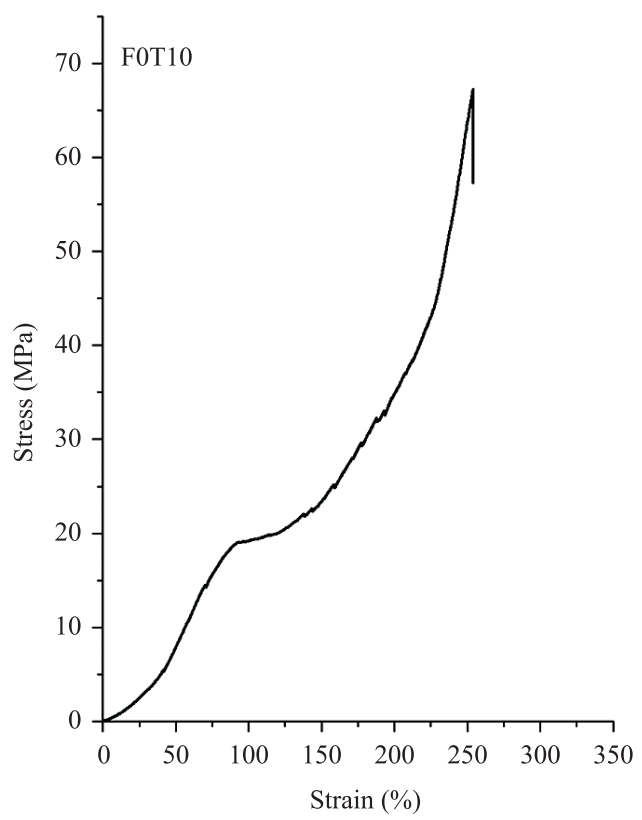

Figure 2. Typical stress versus strain response obtained from a quasi-static compression experiment 
Table 1. Quasi-static compression data showing disc diameter, endplate gap, ultimate compressive stress (UCS), strain at compressive failure and compressive tangent modulus for the 40 IVD specimens tested in the four loading regimes involving flexion and torsion. In the specimen column the letter identifies the tail and the numeral defines the individual motion segment in that tail.

\begin{tabular}{|c|c|c|c|c|c|}
\hline \multicolumn{6}{|c|}{ Flexion $0^{\circ}$ - Torsion $0^{\circ}(\mathrm{FOT} 0)$} \\
\hline Specimen & Diameter (mm) & Gap (mm) & UCS (MPa) & Strain $(\%)$ & Modulus (GPa) \\
\hline B1 & 22 & 5 & 13.9 & 94.3 & 0.02 \\
\hline B2 & 24 & 5 & 15.2 & 95.3 & 0.03 \\
\hline E3 & 19 & 4 & 14.6 & 91.3 & 0.02 \\
\hline $\mathrm{F} 2$ & 24 & 4 & 9.7 & 99.9 & 0.01 \\
\hline G1 & 19 & 7 & 13.6 & 99.5 & 0.03 \\
\hline $\mathrm{H} 2$ & 19 & 5 & 19.2 & 92.1 & 0.03 \\
\hline $\mathrm{J} 1$ & 19 & 7 & 19.0 & 101.9 & 0.03 \\
\hline M1 & 22 & 6 & 16.3 & 89.4 & 0.03 \\
\hline Q1 & 19 & 6 & 35.2 & 99.3 & 0.06 \\
\hline $\mathrm{R} 1$ & 17 & 4 & 23.0 & 91.4 & 0.04 \\
\hline Mean \pm sd & $20 \pm 2$ & $5 \pm 1$ & $18.0 \pm 7.1$ & $95.4 \pm 4.4$ & $0.03 \pm 0.01$ \\
\hline \multicolumn{6}{|c|}{ Flexion $15^{\circ}$ - Torsion $10^{\circ}($ F15T10) } \\
\hline Specimen & Diameter $(\mathrm{mm})$ & Gap (mm) & UCS (MPa) & Strain $(\%)$ & Modulus (GPa) \\
\hline A1 & 21 & 7 & 18.8 & 102.0 & 0.03 \\
\hline $\mathrm{C} 1$ & 22 & 7 & 20.6 & 103.0 & 0.03 \\
\hline D1 & 19 & 4 & 14.6 & 104.4 & 0.02 \\
\hline F1 & 21 & 5 & 14.4 & 99.3 & 0.03 \\
\hline G2 & 21 & 6 & 13.0 & 99.5 & 0.03 \\
\hline H1 & 21 & 6 & 19.7 & 67.2 & 0.05 \\
\hline O1 & 17 & 6 & 23.8 & 93.3 & 0.04 \\
\hline $\mathrm{P} 1$ & 24 & 5 & 23.1 & 86.7 & 0.04 \\
\hline $\mathrm{R} 2$ & 20 & 5 & 24.9 & 72.9 & 0.04 \\
\hline U1 & 20 & 5 & 16.9 & 67.6 & 0.03 \\
\hline Mean \pm sd & $21 \pm 2$ & $6 \pm 1$ & $19.0 \pm 4.2$ & $89.6 \pm 15.0$ & $0.03 \pm 0.01$ \\
\hline \multicolumn{6}{|c|}{ Flexion $15^{\circ}$ - Torsion $0^{\circ}($ F15T0) } \\
\hline Specimen & Diameter (mm) & Gap (mm) & UCS (MPa) & Strain $(\%)$ & Modulus (GPa) \\
\hline $\mathrm{C} 3$ & 23 & 4 & 9.5 & 53.5 & 0.02 \\
\hline D3 & 23 & 6 & 19.2 & 89.4 & 0.02 \\
\hline E1 & 23 & 5 & 17.3 & 95.9 & 0.03 \\
\hline I1 & 23 & 5 & 17.1 & 98.9 & 0.02 \\
\hline $\mathrm{K} 2$ & 19 & 5 & 27.5 & 100.1 & 0.04 \\
\hline $\mathrm{L} 1$ & 17 & 4 & 16.0 & 82.5 & 0.03 \\
\hline N1 & 21 & 6 & 20.3 & 98.9 & 0.03 \\
\hline Q3 & 18 & 6 & 17.7 & 91.9 & 0.04 \\
\hline $\mathrm{S} 2$ & 22 & 6 & 9.9 & 42.4 & 0.03 \\
\hline $\mathrm{T} 1$ & 19 & 6 & 14.6 & 90.3 & 0.03 \\
\hline Mean \pm sd & $21 \pm 2$ & $5 \pm 1$ & $16.9 \pm 5.2$ & $84.4 \pm 20.1$ & $0.03 \pm 0.01$ \\
\hline \multicolumn{6}{|c|}{ Flexion $0^{\circ}$ - Torsion $10^{\circ}($ F0T10) } \\
\hline Specimen & Diameter $(\mathrm{mm})$ & Gap $(\mathrm{mm})$ & UCS (MPa) & Strain $(\%)$ & Modulus (GPa) \\
\hline $\mathrm{C} 2$ & 21 & 6 & 15.3 & 100.0 & 0.02 \\
\hline D2 & 20 & 6 & 19.1 & 88.7 & 0.04 \\
\hline E2 & 20 & 4 & 15.9 & 102.0 & 0.02 \\
\hline $\mathrm{J} 2$ & 17 & 5 & 23.9 & 77.0 & 0.05 \\
\hline $\mathrm{K} 1$ & 19 & 5 & 19.2 & 93.4 & 0.03 \\
\hline $\mathrm{L} 2$ & 19 & 4 & 18.2 & 90.6 & 0.03 \\
\hline M2 & 19 & 5 & 14.5 & 91.5 & 0.03 \\
\hline Q2 & 18 & 4 & 24.6 & 104.6 & 0.04 \\
\hline $\mathrm{S} 1$ & 21 & 5 & 9.3 & 70.3 & 0.02 \\
\hline $\mathrm{T} 2$ & 22 & 6 & 13.2 & 87.8 & 0.03 \\
\hline Mean \pm sd & $20 \pm 2$ & $5 \pm 1$ & $17.3 \pm 4.7$ & $90.6 \pm 10.7$ & $0.03 \pm 0.01$ \\
\hline
\end{tabular}


For $0^{\circ}$ flexion and torsion (F0T0) the ultimate compressive stress ranged from 9.7 to $35.2 \mathrm{MPa}$ with a mean value of $18.0 \pm 7.1 \mathrm{MPa}($ mean $\pm \mathrm{sd} ; \mathrm{n}=10)$. The strain at failure ranged from 89.4 to $101.9 \%$ with a mean value of $95.4 \pm 4.4 \%$ (mean $\pm \mathrm{sd} ; \mathrm{n}=10)$. The tangent modulus ranged from 0.01 to $0.06 \mathrm{GPa}$ with a mean value of $0.03 \pm 0.01 \mathrm{GPa}$ (mean $\pm \mathrm{sd} ; \mathrm{n}=10$ ).

For the regime of $15^{\circ}$ flexion and $10^{\circ}$ torsion (F15T10) the ultimate compressive stress ranged from 13.0 to $24.9 \mathrm{MPa}$ with a mean value of $19.0 \pm 4.2 \mathrm{MPa}$ (mean $\pm \mathrm{sd} ; \mathrm{n}=10$ ). The strain at failure ranged from 67.2 to $104.4 \%$ with a mean value of $89.6 \pm 15.0 \%$ (mean $\pm \mathrm{sd} ; \mathrm{n}=10$ ). The tangent modulus ranged from 0.02 to $0.05 \mathrm{GPa}$ with a mean value of $0.03 \pm 0.01 \mathrm{GPa}$ (mean $\pm \mathrm{sd} ; \mathrm{n}=10$ ).

A similar pattern was found for the loading regime of $15^{\circ}$ flexion and $0^{\circ}$ torsion (F15T0) the ultimate compressive stress ranged from 9.5 to $27.5 \mathrm{MPa}$ with a mean value of $16.9 \pm 5.2 \mathrm{MPa}($ mean $\pm \mathrm{sd} ; \mathrm{n}=10)$. The strain at failure ranged from 42.4 to $100.1 \%$ with a mean value of $84.4 \pm 20.1 \%$ (mean $\pm \mathrm{sd} ; \mathrm{n}=10$ ). The tangent modulus ranged from 0.02 to $0.04 \mathrm{GPa}$ with a mean value of $0.03 \pm 0.01 \mathrm{GPa}$ (mean $\pm \mathrm{sd} ; \mathrm{n}=10$ ).

For the regime of $0^{\circ}$ flexion and $10^{\circ}$ torsion (F0T10) the ultimate compressive stress ranged from 9.3 to 24.6 MPa with a mean value of $17.3 \pm 4.7 \mathrm{MPa}$ (mean $\pm \mathrm{sd} ; \mathrm{n}=10)$. The strain at failure ranged from 70.3 to $104.6 \%$ with a mean value of $90.6 \pm 10.7 \%$ (mean $\pm \mathrm{sd} ; \mathrm{n}=10$ ). The tangent modulus ranged from 0.02 to $0.05 \mathrm{GPa}$ with a mean value of $0.03 \pm 0.01 \mathrm{GPa}$ (mean $\pm \mathrm{sd} ; \mathrm{n}=10)$.

Statistical analysis by means of ANOVA among all the loading regimes and t-tests between the 6 possible combinations of loading regimes failed to indicate any significant difference for all three parameters, i.e. ultimate compressive stress, strain at failure and compressive tangent modulus.

Cyclic tests: The values for the threshold life (in number of cycles) for each of the 40 motion segments in the four loading regimes of flexion and torsion are presented in Table 2. For the regime of $0^{\circ}$ flexion and $0^{\circ}$ torsion (F0T0) the threshold life ranged from 1665 to 7630 with a mean value of $4534 \pm 1736$ (mean \pm sd, $\mathrm{n}=10$ ). For the loading regime of $15^{\circ}$ flexion and $10^{\circ}$ torsion (F15T10), the threshold life ranged from 362 to 7109 , with a mean value of $2973 \pm 1844$ (mean \pm sd, $\mathrm{n}=10$ ). The third regime, $15^{\circ}$ flexion and $0^{\circ}$ torsion (F15T0), produced a threshold life in the range of 1606 to 6497, with a mean value of $4002 \pm 1831$ (mean $\pm \mathrm{sd}$, $\mathrm{n}=10$ ). The loading regime of $0^{\circ}$ flexion and $10^{\circ}$ torsion (F0T10), produced a threshold life in the range of 610 to 4505 , with a mean value of $2443 \pm 1282$ (mean \pm sd, $\mathrm{n}=10$ ). The mean values are also presented in graphical form in Figure 3.
The ANOVA analysis for the four different loading regimes indicated significant differences $(p=3.6 \%)$ at the level of $5 \%$. Furthermore, the t-test analysis indicated that the paired regimes F0T0/F15T10 and F15T0/F0T10 were significantly different at the $1 \%$ level, with $\mathrm{p}$ values of $0.2 \%$ and $0.1 \%$ respectively. Also, the t-test analysis indicated a significant difference between the F0T0 and the F0T10 regimes at a level of $1 \%$ with a $\mathrm{p}$ value of $0.1 \%$. However, the t-test analysis failed to indicate any significant difference between the $\mathrm{F} 0 \mathrm{~T} 0$ and $\mathrm{F} 15 \mathrm{~T} 0$ regimes at a level of $5 \%, p=51 \%$. The $t$-test analysis also failed to indicate any significant difference at the level of 5\% for comparison between the pairs of loading regimes $\mathrm{F} 15 \mathrm{~T} 10 / \mathrm{F} 15 \mathrm{~T} 0$ and F15T10/F0T10, with $\mathrm{p}$ values of $23 \%$ and $47 \%$, respectively.

\section{Discussion}

The methodology developed in this study has provided a means of assessing the relative influence of different mechanical constraints in reducing the load-bearing ability of the disc under both quasi-static and cyclic displacement.

An experimental difficulty experienced with the present methodology was the accurate positioning of the specimen in the testing machine while avoiding the introduction of any pre-test compression or tension. In the quasi-static tests the wide range of strain values obtained at failure can be explained by the very small loads generated in the low modulus 'toe-in' region combined with the use of a load cell of sufficient

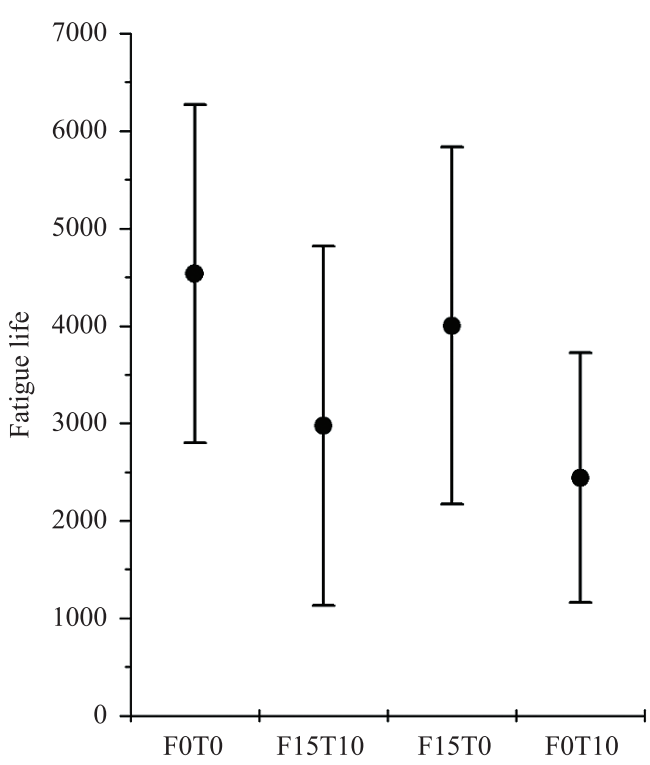

Figure 3. Mean values of threshold life obtained for cyclic loading incorporating flexion and torsion. 
Table 2. Cyclic compression data showing disc diameter, endplate gap and threshold life for the 40 IVD specimens tested in the four loading regimes involving flexion and torsion. In the specimen column, the letter identifies the tail and the numeral defines the individual motion segment in that tail.

\begin{tabular}{|c|c|c|c|}
\hline \multicolumn{4}{|c|}{ Flexion $0^{\circ}$ - Torsion $0^{\circ}($ F0T0 $)$} \\
\hline Specimen & Diameter (mm) & Gap (mm) & Threshold Life (cycles) \\
\hline A2 & 21 & 6 & 3018 \\
\hline $\mathrm{C} 2$ & 19 & 7 & 7630 \\
\hline D2 & 19 & 5 & 4207 \\
\hline E1 & 20 & 5 & 6214 \\
\hline $\mathrm{G} 2$ & 18 & 5 & 4855 \\
\hline $\mathrm{I} 2$ & 20 & 6 & 5869 \\
\hline $\mathrm{J} 1$ & 22 & 6 & 3149 \\
\hline L1 & 20 & 5 & 1665 \\
\hline $\mathrm{O} 1$ & 20 & 5 & 4047 \\
\hline $\mathrm{R} 2$ & 17 & 5 & 4692 \\
\hline Mean \pm sd & $20 \pm 1$ & $6 \pm 1$ & $4534 \pm 1736$ \\
\hline \multicolumn{4}{|c|}{ Flexion $15^{\circ}$ - Torsion $10^{\circ}($ F15T10) } \\
\hline Specimen & Diameter (mm) & Gap (mm) & Threshold Life (cycles) \\
\hline A1 & 23 & 6 & 1785 \\
\hline $\mathrm{C} 1$ & 22 & 6 & 7109 \\
\hline D1 & 18 & 5 & 1761 \\
\hline E2 & 19 & 6 & 2007 \\
\hline G1 & 20 & 5 & 3984 \\
\hline I1 & 18 & 6 & 3211 \\
\hline $\mathrm{J} 2$ & 19 & 5 & 2191 \\
\hline $\mathrm{L} 2$ & 18 & 4 & 362 \\
\hline $\mathrm{O} 2$ & 17 & 4 & 3328 \\
\hline R1 & 20 & 6 & 3992 \\
\hline Mean \pm sd & $19 \pm 2$ & $5 \pm 1$ & $2973 \pm 1844$ \\
\hline
\end{tabular}

\begin{tabular}{|c|c|c|c|}
\hline \multicolumn{4}{|c|}{ Flexion $15^{\circ}$ - Torsion $0^{\circ}($ F15T0) } \\
\hline Specimen & Diameter $(\mathbf{m m})$ & Gap (mm) & Threshold Life (cycles) \\
\hline B1 & 22 & 6 & 1606 \\
\hline $\mathrm{F} 1$ & 18 & 5 & 1977 \\
\hline $\mathrm{H} 1$ & 16 & 5 & 6497 \\
\hline $\mathrm{K} 1$ & 22 & 5 & 2946 \\
\hline M2 & 22 & 6 & 1753 \\
\hline $\mathrm{N} 2$ & 22 & 5 & 5055 \\
\hline $\mathrm{P} 1$ & 20 & 6 & 4013 \\
\hline Q2 & 17 & 5 & 5877 \\
\hline $\mathrm{S} 2$ & 20 & 5 & 4567 \\
\hline $\mathrm{T} 1$ & 19 & 5 & 5728 \\
\hline Mean \pm sd & $20 \pm 2$ & $5 \pm 1$ & $4002 \pm 1831$ \\
\hline \multicolumn{4}{|c|}{ Flexion $0^{\circ}$ - Torsion $10^{\circ}($ F0T10) } \\
\hline Specimen & Diameter $(\mathrm{mm})$ & Gap (mm) & Threshold Life (cycles) \\
\hline B2 & 24 & 4 & 610 \\
\hline $\mathrm{F} 2$ & 20 & 5 & 705 \\
\hline $\mathrm{H} 2$ & 19 & 5 & 4505 \\
\hline $\mathrm{K} 2$ & 19 & 5 & 2456 \\
\hline M1 & 18 & 5 & 1224 \\
\hline N1 & 20 & 6 & 2647 \\
\hline $\mathrm{P} 2$ & 20 & 5 & 3831 \\
\hline Q1 & 21 & 6 & 2687 \\
\hline $\mathrm{S} 1$ & 22 & 4 & 2533 \\
\hline $\mathrm{T} 2$ & 16 & 4 & 3237 \\
\hline Mean \pm sd & $20 \pm 2$ & $5 \pm 1$ & $2443 \pm 1282$ \\
\hline
\end{tabular}


capacity to operate in the high load range. In this 'toe-in' region the actuator could be moved distances of the order of a millimetre with only minor changes in the measured load. This uncertainty in displacement measurement clearly limits the accuracy of the strain values derived from the endplate separation.

For satisfactory biomechanical function the disc must maintain a minimum level of hydration. Cyclic compression, without the opportunity for fluid resorption to take place, will result in progressive dehydration. Keeping the disc moist (as was done in the present study) will help reduce the rate of dehydration. However, ultimately the mechanical forces producing outflow will overcome the physicochemical forces driving the rehydration process, at least until an equilibrium is reached between the externally applied load and the internal swelling pressure corresponding to the state of consolidation reached under that particular mechanical history. Any further decay in stress could then be attributed to some form of structure damage which has reduced the intrinsic load-bearing ability of the disc. This interpretation is further supported by the observation that prior to cyclic loading only a limited degree of easy flexion of the IVD was possible. However, following cyclic testing and rehydration for a period of 12 hours the disc retained a high degree of laxity which could not be accounted for solely by fluid exudation.

Although we have employed a regime of cyclic loading, this was not aimed at establishing a fatigue life in the strict sense of the word. Rather, the objective of the present study was to assess the influence of different combinations of mechanical constraint upon the cyclic load-bearing ability of the disc. Any direct comparison of the cyclic threshold values presented in the present work with 'fatigue' data published in the literature (Gordon et al., 1991; Green et al., 1993; Hansson et al., 1987) would not be possible as the limiting criteria employed were significantly different.

Direct comparison with other studies is also hindered by differences in the in vitro setup employed to conduct the cyclic loading experiments. For example, Callaghan and McGill (2001) used load control whilst the present experiments were conducted under displacement control. Load control experiments are better viewed as cyclic creep procedures whereas displacement control would be equivalent to cyclic stress relaxation. Both experiments yield viscoelastic responses which are transposable. Both load control and displacement control will have relevance to the disc's mechanical environment in vivo since periods of sustained, constant and variable loading will be mixed with movements involving displacements between fixed limits. For the purpose of comparing the relative influence of flexion and torsion under cyclic compression the choice of load or displacement control is probably less important than having a consistently reproducible testing procedure. We accordingly chose the easier displacement controlled experiment.

The present methodology of imposing pure compression in combination with anterior hyper-flexion and hyper-torsion, whilst obviously non physiological, was expected to induce readily observed changes in the functional properties of the disc as quantified in single quasi-static or cyclic compressive loading. Pure compression of the disc is translated into tensile loading of the collagenous fibres in the annulus. Torsion will impose additional tensile loading on half of the obliquely arranged fibres in the lamellar structure of the annulus. Anterior flexion would impose additional tensile loading on the posterior fibres of the annulus whilst the anterior fibres would undergo increased compression and outwards bulging.

Statistical analysis failed to indicate any difference between the four loading regimes in single monotonic quasi-static compression. This finding could imply that the extra tensile loading on the collagenous fibres of the annular wall resulting from the added effects of torsion and flexion was still relatively small compared to the tensile forces arising from radial bulging in the single quasi-static compression test. An alternative explanation could be that loading half of the fibres in the whole of the IVD wall as occurs in torsion is similar to loading the posterior half of the annular wall as in anterior flexion, and this would be reflected in the quantified mechanical parameters. However, the fact that the quasi-static loading regimes F0T0 and F15T10 showed similar results indicate that the first explanation is more reasonable.

By contrast, cyclic compressive loading resulted in significant differences among the four loading regimes. Our analysis (Figure 3) indicates that the loading regime of cyclic compression plus torsion only (F0T10) is more severe in reducing the load-bearing ability of the disc than the regime of cyclic compression plus flexion only (F15T0). The fact that the statistical analysis failed to indicate any significant difference between the pairs of loading regimes F15T10/F15T0 and F15T10/F0T10, is probably explained by normal biological variations. Indeed the paired t-test analysis, which eliminated interspecimen variability, i.e. in the paired regimes F0T0/F15T10 and F15T0/F0T10, were significantly different (see Figure 3). In summary, the cyclic data indicates that torsion has potential to inflict greater damage than flexion, a fact that is consistent with the relatively larger in vivo anatomical limitations on this specific type of movement.

It is important to stress that the results obtained in the present study using caudal disc subjected to 
either quasi-static or cyclic compression will not allow us to predict the behaviour of the human lumbar disc in vivo. Whereas the lumbar disc is highly asymmetrical the bovine caudal disc is almost circular in cross-section. There is a difference too in the collagen angle in the alternating lamellae. In the human lumbar disc it is about $65^{\circ}$ to the sagittal plane whereas in the caudal disc we found it to be around $52^{\circ}$. The loading conditions in the caudal disc will also differ substantially from those in the lumbar disc. However the overall similarity of structural plan of the bovine and human discs, their cell phenotype, their composition, aspect ratio and loaded pressure profiles (Yu et al., 2003) all clearly imply a reliance on common biomechanical mechanisms for function, namely the confinement of a pressurized nucleus by the surrounding annular wall. Thus, insights gained from testing caudal units should at the very least have some principled application to the behaviour of human discs.

\section{Conclusions}

We have shown that cyclic loading provides a more sensitive measure of the influence of potentially damaging mechanical parameters for the IVD than is provided by a single quasi-static test. We offer an experimental technique that provides evidence of the effects of different loading regimes on the deterioration in functional properties of the IVD, and thus has the potential to further enhance our understanding of the initiating mechanisms of disc failure. This model, or variations of it, in conjunction with detailed structural analysis, should help define more precisely the role of the biomechanical environment in contributing to disc malfunction and thus to the prevention of injury with its ensuing degenerative cascade in this complex biomechanical organ.

\section{Acknowledgements}

The authors gratefully acknowledge the support of the Auckland Medical Research Foundation and the Brazilian Government (CAPES/MEC).

\section{References}

Adams MA, Hutton WC. Prolapsed intervertebral disc. A hyperflexion injury 1981 Volvo Award in Basic Science. Spine. 1982; 7:184-91. PMid: 7112236

Adams MA, Hutton WC. The effect of fatigue on the lumbar intervertebral disc. Journal of Bone \& Joint Surgery. 1983; 65:199-203. PMid: 6826631

Adams MA, Hutton WC. Gradual disc prolapse. Spine. 1985; 10:524-31. PMid: 4081867

Callaghan JP, McGill SM. Intervertebral disc herniation: studies on a porcine model exposed to highly repetitive flexion/extension motion with compressive force. Clinical Biomechanics. 2001; 16:28-37. PMid: 11114441

Farfan HF, Cossette JW, Robertson GH, Wells RV, Kraus $\mathrm{H}$. The effects of torsion on the lumbar intervertebral joints: the role of torsion in the production of disc degeneration. The Journal of Bone \& Joint Surgery. 1970; 52:468-97. PMid: 5425641

Gordon SJ, Yang KH, Mayer PJ, Mace Junior AH, Kish VL, Radin EL. Mechanism of disc rupture. A preliminary report. Spine. 1991; 16:450-6. PMid: 2047918

Green TP, Adams MA, Dolan P. Tensile properties of the annulus fibrosus II. Ultimate tensile strength and fatigue life. European Spine Journal. 1993; 2:209-14. PMid: 20058407

Hansson TH, Keller TS, Spengler DM. Mechanical behavior of the human lumbar spine. II. Fatigue strength during dynamic compressive loading.Journal of Orthopaedic Research. 1987; 5:479-87. PMid: 3681522

Liu YK, Goel VK, Dejong A, Njus G, Nishiyama K, Buckwalter J. Torsional fatigue of the lumbar intervertebral joints. Spine. 1985; 10:894-900. PMid: 3832457

Nachemson A, Elfström G. Intravital dynamic pressure measurements in lumbar discs. A study of common movements, maneuvers and exercises. Scandinavian Journal of Rehabilitation Medicine - Supplement. 1970; 1:1-40.

Skaggs DL, Weidenbaum M, Iatridis JC, Ratcliffe A, Mow VC. Regional variation in tensile properties and biochemical composition of the human lumbar anulus fibrosus. Spine. 1994; 19:1310-9. PMid: 8066509

Yu C-Y, Tsai K-H, Hu W-P, Lin R-M, Song H-W, Chang G-L. Geometric and morphological changes of the intervertebral disc under fatigue testing. Clinical Biomechanics. 2003; 18:S3-9. PMid: 12828908

\footnotetext{
Authors

Helio Schechtman*

Programa de Computação Científica, Fundação Oswaldo Cruz - FIOCRUZ, Av. Brasil, 4365, Manguinhos, CEP 21040-360, Rio de Janeiro, RJ, Brazil.

Peter Alexander Robertson

Department of Orthopaedic Surgery, Auckland Hospital, Auckland, New Zealand.

Department of Chemical and Materials Engineering, Department of Mechanical Engineering, University of Auckland, Auckland, New Zealand.
} 